\title{
Assessesment of subclavian arteries: Usefulness of coronal view in prenatal ultrasound diagnosis
}

\author{
Savirón-Cornudella $\mathrm{R}^{1 *}$, Lerma Puertas $\mathrm{D}^{2}$, Corona Bellostas $\mathrm{C}^{3}$, Cotaina Gracia $\mathrm{L}^{2}$, Jiménez Montañez Lªnd De León-Luis J6 \\ ${ }^{1}$ Fetal Medicine Unit, Department of Obstetrics and Gynecology, Hospital General de Villalba, Madrid, Spain \\ ${ }^{2}$ Fetal Medicine Unit, Department of Obstetrics and Gynecology, Hospital Universitario Miguel Servet, Zaragoza, Spain \\ ${ }^{3}$ Pediatric surgery, Department of Pediatric Surgery, Hospital General Universitario Gregorio Marañón, Madrid, Spain \\ ${ }^{4}$ Pediatric Echocardiography, Department of Pediatrics, Hospital General Universitario Miguel Servet, Zaragoza, Spain \\ ${ }^{5}$ Fetal Medicine Unit, Department of Obstetrics and Gynecology, Hospital General Universitario Gregorio Marañón, Madrid, Spain
}

\begin{abstract}
The axial view is the reference for the diagnosis of vascular anomalies, including affecting subclavian arteries, like the aberrant right subclavian artery (ARSA) or an aberrant left subclavian artery (ALSA). Although axial view allows us to distinguish vascular subclavian arteries anomalies in most cases, we can use the coronal view not only in cases of ARSA but also in cases of ALSA using the same methodology. Therefore, we can say that coronal view help us as an additional aid to support the diagnosis of both vascular anomalies.
\end{abstract}

\section{Introduction}

The improvements in ultrasound's image quality and color doppler and the systematization of ultrasound views, especially in the axial, and in some cases, coronal for the fetal cardiovascular system study, as well as the advances in fetal anatomy study, have allowed a more precise diagnosis of vascular anomalies. Prenatal ultrasound assessment of subclavian arteries allow us to make a diagnosis of an alteration in his way, like the aberrant right subclavian artery (ARSA) or an aberrant left subclavian artery (ALSA).

The aberrant right subclavian artery (ARSA) is that right subclavian artery that, instead of originating from brachiocephalic trunk, it does it from the descending aorta in a retroesophageal path to the right shoulder, being the last of the four supra-aortic trunks.

The aberrant left subclavian artery (ALSA) appears in the context of a type II right aortic arch (type II RAA), that is the most common right aortic arch anomaly [1-3]. The ductus arteriosus is usually placed in the left position and thus close postnatally the vascular ring between the right aortic arch and left ductus arteriosus. The lusory artery arises independently from de Kommerell's diverticulum (partial remainder of the original fourth left aortic arch) from a backplane to the esophagus and crosses the midline towards the left shoulder [4-6].

\section{Prenatal ultrasound diagnosis}

Both ARSA and various aortic arch anomalies have been correlated with increased risk of congenital heart disease and/or chromosomal abnormalities, so the prenatal ultrasound study of subclavian arteries is interesting $[7,8]$. Besides, the postnatal ultrasound study is more complicated because of the pulmonary air and a worse acoustic window. The ultrasound diagnosis of ARSA or ALSA is usually done in the axial view, being the Yagel's three-vessels view with color Doppler, adjusting the PRF application with a low-velocity range $(10-15 \mathrm{~cm} / \mathrm{s})$, and the reference view [9-11]. Although sometimes doubts may arise and there may be necessary views in another planes to support the diagnosis.

The true incidence of ARSA is unknown, but in the general population it seems to range between $0.4-2,2 \%$ being the most common aortic arch anomaly prenatally diagnosed [11]. Most references say that to identify we must perform an axial view with color-Doppler at the three-vessels level and then swing the probe upwards to the right fetal shoulder [12-14].

The three-vessels view is also the key for the diagnosis of right aortic arch anomalies. In type II, the trachea is located between the right aortic arch and left ductus arteriosus deforming the shape of "V" to "U" ("U sign"), forming a vascular ring, where we can also see ALSA leaving the Kommerell's diverticulum to the left shoulder [15].

Also Chaoui has described the longitudinal view of the aortic arch for the ARSA diagnosis. Thus we could see the four supra-aortic trunks instead of the usual three, being the ARSA the last branch of the aortic arch, below of the ductus arteriosus junction. Although this view seems to be more complicated to get, it is probably because the oblique course of the vessel makes it difficult to visualize the ARSA $[11,16]$.

The coronal view with color-Doppler for ARSA and ALSA are "mirror images" because the ARSA goes to right side and the ALSA to left one.

In a coronal view of the thoracic aorta with color Doppler, we can see ARSA emerging independently of the other vessels (left carotid,

Correspondence to: Ricardo Savirón-Cornudella, Fetal Medicine Unit, Department of Obstetrics and Gynecology, Hospital General de Villalba, Madrid, Spain, E-mail: rsaviron@gmail.com

Key words: Ultrasound diagnosis, ALSA, ARSA, coronal view, vascular anomalies Received: December 01, 2017; Accepted: December 26, 2017; Published: December 30, 2017 
left subclavian and right carotid) with a right direction [11]. This view, as described by Leon, allow us to distinguish ARSA from azygous draining into the right superior vena cava and thus avoid false positive [17] (Figure 1).

In the coronal view, using the same methodology as the ARSA, ALSA leaves at Kommerell's diverticulum level in the same plane than thoracic aorta, independently of the other vessels (right carotid, left carotid and left subclavian) with a left direction [18] (Figure 2).

\section{Conclusion}

Although axial view allows us to distinguish vascular subclavian arteries anomalies in most cases, we can use the coronal view not only in cases of ARSA but also in cases of ALSA (in a RAA type II). Therefore, we can say that coronal view help us as an additional aid to support the diagnosis of both vascular anomalies.

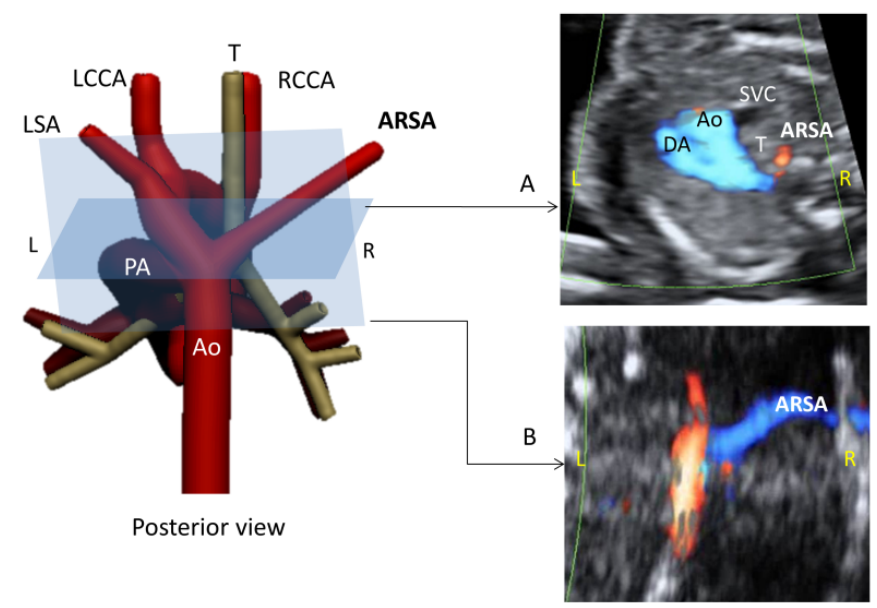

Figure 1. Case of aberrant right subclavian artery (ARSA).

A) Three vessels-trachea view

B) Coronal view. Ao, aorta; PA, pulmonary artery; DA, ductus arteriosus; IV, innominate vein; L, left; LCCA, left common carotid artery; RCCA, right common carotid artery; LSA left subclavian artery; R, right; ARSA, aberrant right subclavian artery; SVC, superior vena cava; $T$, trachea.

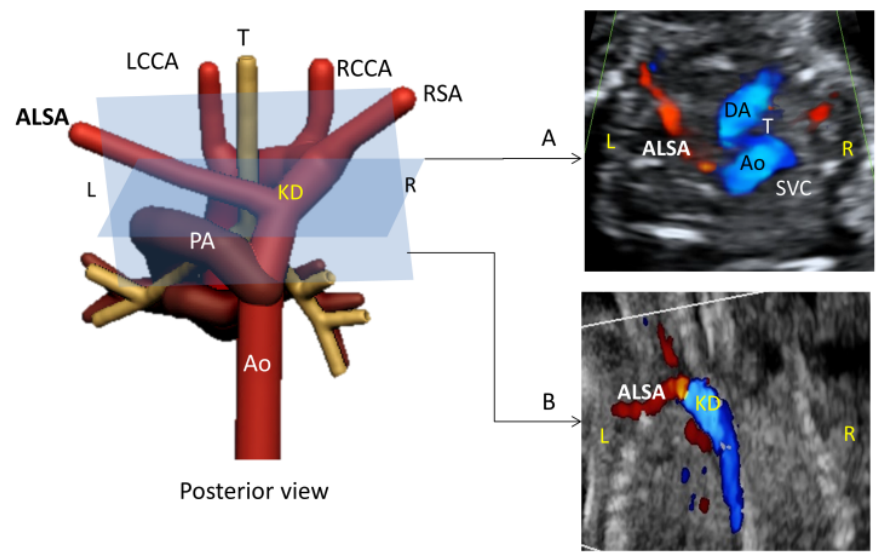

Figure 2. Case of right aortic arch with aberrant left subclavian artery (ALSA).

A) Three vessels-trachea view. Aortic arch appears to the right of the trachea forming a 'U'. B) Coronal view. Ao, aorta; PA, pulmonary artery; DA, ductus arteriosus; IV, innominate vein; L, left; R, right; LCCA, left common carotid artery; RCCA, right common carotid artery; RSA, right subclavian artery; SVC, superior vena cava; T, trachea; KD: Kommerell's diverticulum

\section{References}

1. Berg C, Bender F, Soukup M, Geipel A, Axt-Fliedner R, et al. (2006) Right aortic arch detected in fetal life. Ultrasound Obstet Gynecol 28: 882-889. [Crossref]

2. Galindo A, Nieto O, Nieto MT, Rodríguez-Martín MO, Herraiz I, et al. (2009) Prenatal diagnosis of right aortic arch: associated findings, pregnancy outcome, and clinical significance of vascular rings. Prenat Diagn 29: 975-981. [Crossref]

3. Tuo G, Volpe P, Bava GL, Bondanza S, De Robertis V, et al. (2009) Prenatal diagnosis and outcome of isolated vascular rings. Am J Cardiol 103: 416-419. [Crossref]

4. Kommerell B (1936) Verlagerung des Ösophagus durch eine abnorm verlaufende Arteria subclavia dextra (Arteria lusoria). Fortschr Geb Roentgenstrahlen 54:590-595.

5. Chaoui R, Schneider MB, Kalache KD (2003) Right aortic arch with vascular ring and aberrant left subclavian artery: prenatal diagnosis assisted by three-dimensional power Doppler ultrasound. Ultrasound Obstet Gynecol 22: 661-663. [Crossref]

6. Yoo SJ, Min JY, Lee YH, Roman K, Jaeggi E, et al. (2003) Fetal sonographic diagnosis of aortic arch anomalies. Ultrasound Obstet Gynecol 22: 535-546.[Crossref]

7. McElhinney DB, Clark BJ III, Weinberg PM, Kenton ML, McDonald-McGinn D, et al. (2001) Association of chromosome 22q11 deletion with isolated anomalies of aortic arch laterality and branching. $J$ Am Coll Cardiol 37: 2114-2119. [Crossref]

8. Rauch R, Rauch A, Koch A, Zink S, Kaulitz R, et al. (2004) Laterality of the aortic arch and anomalies of the subclavian artery: reliable indicators for $22 \mathrm{q} 11.2$ deletion syndromes? Eur J Pediatr 163: 642-645. [Crossref]

9. Yagel S, Cohen SM, Achiron R (2001) Examination of the fetal heart by five short-axis views: a proposed screening method for comprehensive cardiac evaluation. Ultrasound Obstet Gynecol 17: 367-369. [Crossref]

10. Chaoui R, McEwing R (2003) Three cross-sectional planes for fetal color Doppler echocardiography. Ultrasound Obstet Gynecol 21: 81-93. [Crossref]

11. De León-Luis J, Gámez F, Bravo C, Tenías JM, Arias Á, et al. (2014) Second-trimester fetal aberrant right subclavian artery: original study, systematic review and metaanalysis of performance in detection of Down syndrome. Ultrasound Obstet Gynecol 44: 147-153. [Crossref]

12. Chaoui R, Heling KS, Sarioglu N, Schwabe M, Dankof A, et al. (2005) Aberrant right subclavian artery as a new cardiac sign in second- and third-trimester fetuses with Down syndrome. Am J Obstet Gynecol 192: 257-263. [Crossref]

13. Borenstein M, Cavoretto P, Allan L, Huggon I, Nicolaides KH (2008) Aberrant right subclavian artery at $11+0$ to $13+6$ weeks of gestation in chromosomally normal and abnormal fetuses. Ultrasound Obstet Gynecol 31: 20-24. [Crossref]

14. Rembouskos G, Passamonti U, De Robertis V, Tempesta A, Campobasso G, et al (2012) Aberrant right subclavian artery (ARSA) in unselected population at first and second trimester ultrasonography. Prenat Diagn 32: 968-975. [Crossref]

15. Chaoui R, Rake A, Heling KS (2008) Aortic arch with four vessels: aberrant right subclavian artery. Ultrasound Obstet Gynecol 31: 115-117. [Crossref]

16. Quarello E, Carvalho JS (2009) Prenatal diagnosis of an aberrant right subclavian artery: four vessels arising from the aortic arch? Ultrasound Obstet Gynecol 33: 492493. [Crossref]

17. De Leon-Luis J, Bravo C, Gamez F, Ortiz-Quintana L (2012) Coronal view as a complementary ultrasound approach for prenatal diagnosis of aberrant right subclavian artery. Ultrasound Obstet Gynecol 40: 370-371.

18. Achiron R, Rotstein Z, Heggesh J, Bronshtein M, Zimand S, et al. (2002) Anomalies of the fetal aortic arch: a novel sonographic approach to in-utero diagnosis. Ultrasound Obstet Gynecol 20: 553-557. [Crossref]

Copyright: (C2017 Savirón-Cornudella R. This is an open-access article distributed under the terms of the Creative Commons Attribution License, which permits unrestricted use, distribution, and reproduction in any medium, provided the original author and source are credited. 